\title{
Facial palsy in individuals with thalidomide embryopathy: frequency and characteristics
}

\author{
L SJÖGREEN $^{1}$, S KILIARIDIS ${ }^{2}$ \\ ${ }^{1}$ Mun-H-Center Orofacial Resource Centre for Rare Diseases and Department of Speech Pathology, Institute of \\ Neuroscience and Physiology, Sahlgrenska Academy at Gothenburg University, Sweden, and ${ }^{2}$ Department of \\ Orthodontics, Dental School, University of Geneva, Switzerland
}

\begin{abstract}
Background: Earlier studies have shown that individuals with thalidomide embryopathy can have skeletal deformities, ear and eye aberrations, and facial palsy. This study aimed to survey the frequency and characteristics of facial palsy in this group of individuals.

Participants: Thirty-one individuals with thalidomide embryopathy (age range, 45-47 years) and 25 healthy adults (age range, $41-56$ years; mean age \pm standard deviation, $49 \pm 4.2$ years).

Main outcome measures: Voluntary facial movements, lip force and three-dimensional lip motion analysis.

Results and conclusion: Four of the thalidomide embryopathy individuals (13 per cent) had congenital facial palsy. All four had eye aberrations, three had ear anomalies and one had a limb anomaly. Individuals with thalidomide embryopathy without a clinical diagnosis of facial impairment had significantly weaker lips and more restricted lip mobility than healthy controls. This study contributes to the overall knowledge of thalidomide embryopathy by adding a description of how facial expression can be affected in this condition.
\end{abstract}

Key words: Thalidomide; Embryopathies; Facial Palsy

\section{Introduction}

In 1961, it was discovered that women who had taken the drug thalidomide in early pregnancy gave birth to children with multiple anomalies. ${ }^{1}$

Strömland and Miller's 1993 study of 86 Swedish individuals with thalidomide embryopathy found that the drug caused not only skeletal deformities but also eye aberrations (in 54 per cent) and facial palsy (in 17 per cent). ${ }^{2}$ The authors noted that facial palsy, ocular motility defects and abnormal lacrimation occurred in individuals who had been exposed to thalidomide early in their gestation period, but not in those who had isolated anomalies occurring as a result of later exposure. Strömland and Miller confirmed that thalidomide exerts its effects on the development of the cranial nerves early in the teratogenic period, probably mainly during the fourth week of development.

The present study of the occurrence of facial palsy in individuals with thalidomide embryopathy was part of a multidisciplinary follow-up investigation of a subset of Swedish thalidomide embryopathy individuals, performed approximately 50 years after thalidomide was introduced to the market. ${ }^{3,4}$ Facial palsy has previously been recognised as an effect of thalidomide embryopathy but has not been described in any detail.
Therefore, the present study aimed to survey the frequency and characteristics of facial palsy in this group of individuals.

\section{Materials and methods}

Individuals with thalidomide embryopathy were invited to participate in a multidisciplinary study via a letter distributed by The Swedish Association of Thalidomide Embryopathy. At that time, there were 108 members, of which 84 were on the mailing list. Fifty individuals replied to the invitation, and 31 (18 men and 13 women) took part in the study. All were aged between 45 and 47 years. Congenital anomalies were common and affected the upper limb (27 individuals), lower limb (7), ears (9) and eyes (12).

The results from the examinations of individuals without facial impairment were compared to those from 25 healthy adults (seven men and 18 women; age range, 41-56 years; mean age \pm standard deviation, $49 \pm 4.2$ years)

The examinations were conducted at Mun-H-Center, a national orofacial resource centre for rare diseases.

Informed consent was obtained from each participant, and the study was approved by the ethics 
committee of the Medical Faculty at the University of Gothenburg.

\section{Voluntary facial movements}

Video recordings of voluntary facial movements and facial muscles at rest were independently evaluated by two speech-language pathologists according to the definitions described in the Sunnybrook Facial Grading System. ${ }^{5,6}$ In cases of disagreement on any variable, the two examiners watched the video recording together and made a consensus decision. Both examiners knew beforehand whether the individual had thalidomide embryopathy or not.

The facial expressions studied were gentle eye closure, open mouthed smile, snarl and lip pucker. The participants repeated the facial expressions twice with a short break in between. The degree of muscle excursion during voluntary movements was evaluated on a five-point scale with the following definitions: $1=$ unable to initiate movement; $2=$ initiates slight movement; 3 = initiates movement with mid-excursion; $4=$ movement almost complete; and $5=$ movement complete. Any synkinetic movements accompanying the voluntary movements were also recorded if present. Resting symmetry was noted while the patient looked at a picture for 30 seconds, and was described as normal or affected. Recordings were made with two calibrated digital video cameras (Sony XC-HR50; Sony, Tokyo, Japan). The two cameras were positioned approximately $80 \mathrm{~cm}$ in front of the participant and $25 \mathrm{~cm}$ apart.

\section{Lip mobility}

The three-dimensional position of the oral commissures was measured from the video recordings using SmartEye Pro 3.7 Mimic Muscle Evaluation software (SmartEye, Gothenburg, Sweden). ${ }^{7,8}$ This information was used to calculate mouth width (i.e. the distance between the oral commissures), mouth width change during different facial expressions compared to the rest position, and mouth width asymmetry. The method we used for computerised evaluation of lip mobility has been previously described in detail by Sjögreen et ${ }^{8} .^{8}$

\section{Lip force}

Lip force was measured using an LF100 instrument (Detektor, Göteborg, Sweden) connected to an oral screen (Ulmer model; Dentarum, Pforzheim, Germany). ${ }^{8,9}$ Patients were seated in a stable position and instructed to keep the oral screen inside their lips while the examiner pulled the handle. The LF100 instrument recorded the maximum value measured during 10 seconds. The best of three measurements was saved. The LF100 instrument was not included in the study from outset, and therefore lip force was only measured in 29 patients. All lip force measurements were made by the same speech-language pathologist (LS).

\section{Statistical analysis}

The Statistical Package for the Social Sciences for Windows (version 15.0) software program was used to calculate descriptive statistics and to analyse group differences (using the Mann-Whitney U test) and correlations between groups (using Pearson's correlation coefficient).

\section{Results and analysis}

\section{Voluntary facial movements}

Six of the 31 individuals with thalidomide embryopathy (19 per cent) had a Sunnybrook Facial Grading System score of less than 4 on any side, or both sides, for one or more of the facial expressions studied (Table I). Five had a known diagnosis of facial palsy and one had Parkinson's disease.

Case seven had an acquired, unilateral facial palsy due to a stroke. The only remaining symptom was delayed muscle contraction on the right side during open-mouthed smiling. Voluntary lip movements were complete and the face was symmetrical at rest.

Case 11 had a bilateral facial palsy, congenital on the left side and acquired on the right due to ear surgery. All facial muscles were severely affected.

Case 16 had a congenital, unilateral facial palsy severely affecting the muscles elevating the left corner of the mouth. Lip pucker was performed with complete movements on both sides but the mouth deviated to the healthy side.

Case 24 had a congenital facial palsy affecting only the muscle depressor labii inferioris on the right side.

\begin{tabular}{|c|c|c|c|c|c|c|c|}
\hline \multirow{3}{*}{ Case no } & \multirow{3}{*}{ Sex } & \multicolumn{5}{|c|}{$\begin{array}{l}\text { TABLE I } \\
\text { INOSED FA }\end{array}$} & \\
\hline & & \multirow[t]{2}{*}{ Diagnosis } & \multirow[t]{2}{*}{ Asym at rest? } & \multicolumn{4}{|c|}{ SFGS score (left/right) } \\
\hline & & & & Eye closure & OM smile & Snarl & Pucker \\
\hline 7 & M & Unilateral facial palsy & No & $5 / 5$ & $5 / 5$ & $5 / 5$ & $5 / 5$ \\
\hline 11 & M & Bilateral facial palsy & Yes & $4 / 4$ & $2 / 1$ & $1 / 1$ & $1 / 1$ \\
\hline 16 & $\mathrm{~F}$ & Unilateral facial palsy & Yes & $5 / 3$ & $5 / 1$ & $5 / 3$ & $5 / 5$ \\
\hline 19 & $\mathrm{~F}$ & Parkinson's disease & No & $5 / 3$ & $3 / 3$ & $3 / 3$ & $5 / 5$ \\
\hline 24 & M & Unilateral facial palsy & No & $5 / 5$ & $4 / 5$ & $3 / 5$ & $5 / 5$ \\
\hline 25 & $\mathrm{~F}$ & Bilateral facial palsy & Yes & $5 / 4$ & $4 / 3$ & $5 / 3$ & $5 / 5$ \\
\hline
\end{tabular}

*Sunnybrook Facial Grading System (SFGS) score of less than 4 for at least one facial expression; see text for explanation of scores. $\mathrm{TE}=$ thalidomide embryopathy; no = number; Asym = asymmetrical; $\mathrm{OM}=$ open mouthed; $\mathrm{M}=$ male; $\mathrm{F}=$ female 
Case 25 had an asymmetrical, bilateral facial palsy, congenital on the right side and acquired on the left. The congenital facial palsy was more severe than the acquired, and the face was asymmetrical at rest.

Case 19 had hypokinetic facial movements because of Parkinson's disease. None of the participants showed synkinetic movements.

All four individuals with congenital facial palsy had ocular motility defects (Duane syndrome) and anomalous tearing, ${ }^{4}$ three had ear anomalies, one had an upper limb anomaly, and none had lower limb anomalies. Two with bilateral facial palsy had mild dysarthria (cases 11 and 25). Upper face involvement (cases 11, 16 and 25) or impairment of a single branch of the facial nerve (case 24) indicated that the facial palsy was peripheral in these cases.

\section{Lip mobility}

Table II gives individual measures of lip mobility, in terms of mouth width, mouth width change and mouth width asymmetry, for the six participants with thalidomide embryopathy and facial impairment. Table III presents results for the same parameters for those participants with thalidomide embryopathy who did not have a diagnosed facial impairment, and also for healthy adult controls. The healthy adults had a broader smile and a larger mouth width change in an open mouthed smile than the thalidomide embryopathy

\begin{tabular}{|c|c|c|c|c|}
\hline \multicolumn{5}{|c|}{$\begin{array}{l}\text { LIP MOBILITY RESULTS*: TE CASES WITH DIAGNOSED } \\
\text { FACIAL PALSY }{ }^{\dagger}\end{array}$} \\
\hline Case no & $\begin{array}{l}\text { SFGS score } \\
\quad(\mathrm{L} / \mathrm{R})\end{array}$ & $\begin{array}{l}\mathrm{MW} \\
(\mathrm{mm})\end{array}$ & $\begin{array}{c}\mathrm{MWC} \\
(\mathrm{mm})\end{array}$ & $\begin{array}{l}\text { MWA } \\
(\%)\end{array}$ \\
\hline \multicolumn{5}{|c|}{ Mouth at rest } \\
\hline 7 & & 47.9 & - & 4.3 \\
\hline 11 & & 53.0 & - & 5.8 \\
\hline 16 & & 49.9 & - & $20.4^{\ddagger}$ \\
\hline 19 & & 44.4 & - & $19.5^{\ddagger}$ \\
\hline 24 & & $53.9^{* *}$ & - & 4.1 \\
\hline 25 & & $43.7^{* *}$ & - & 2.9 \\
\hline \multicolumn{5}{|c|}{$\begin{array}{l}\text { Open mouthed } \\
\text { smile }\end{array}$} \\
\hline 7 & $5 / 5$ & 62.0 & 14.1 & 1.2 \\
\hline 11 & $2 / 1$ & $49.3^{\ddagger}$ & $-3.6^{\ddagger}$ & $6.7^{* *}$ \\
\hline 16 & $5 / 1$ & $58.7^{* *}$ & $8.8^{\ddagger}$ & $6.4^{* *}$ \\
\hline 19 & $3 / 3$ & $53.0^{* *}$ & $8.6^{\ddagger}$ & $14.5^{\ddagger}$ \\
\hline 24 & $4 / 5$ & 70.9 & 17.0 & 0.7 \\
\hline 25 & $4 / 3$ & $57.8^{* *}$ & 14.2 & 4.3 \\
\hline \multicolumn{5}{|c|}{ Lip pucker } \\
\hline & $5 / 5$ & 27.3 & -20.6 & 4.6 \\
\hline 11 & $1 / 1$ & $47.9^{*}$ & $-5.1^{\ddagger}$ & 9.2 \\
\hline 16 & $5 / 5$ & 28.5 & -21.4 & $42.1^{\ddagger}$ \\
\hline 19 & $5 / 5$ & 28.9 & $-15.4^{* *}$ & $24.5^{* *}$ \\
\hline 24 & $5 / 5$ & 30.5 & -23.3 & 15.5 \\
\hline 25 & $5 / 5$ & 26.5 & -17.2 & 27.5 \\
\hline
\end{tabular}

* Mouth width (MW), mouth width change from rest to maximal expression (MWC) and relative mouth width asymmetry (MWA), from three-dimensional motion analysis of lip mobility. ${ }^{\dagger}$ Sunnybrook Facial Grading System (SFGS) score of less than 4 for at least one facial expression. "Value is $>2$ standard deviations (SDs) lower than mean for healthy controls; ${ }^{* *}$ value is $>1$ SD lower than mean for healthy controls. $\mathrm{TE}=$ thalidomide embryopathy; no = number; $\mathrm{L}=$ left; $\mathrm{R}=$ right individuals without facial impairment $(p=0.002$, $z=-3.134)$; however, there was no difference between these groups concerning mouth width in lip pucker $(p=0.171, z=-1.368)$ or at rest $(p=0.915$, $z=-0.107)$. Three individuals with facial impairment had a mouth width change in an open mouthed smile and in a lip pucker that was more than two standard deviations lower than the mean of the healthy group. In the group of individuals with thalidomide embryopathy and no recognised facial impairment $(n=25)$, seven individuals had values lower than two standard deviations from the mean of the healthy adults in an open mouthed smile, and one in a lip pucker (borderline).

\section{Lip force}

The individuals with thalidomide embryopathy and no recognised facial impairment had weaker lips than the healthy adults $(p=0.004, z=-2.481)$ (Figure 1). There was a weak but significant correlation between lip force and mouth width change in an open mouthed smile ( $p=0.006, r=371)$ but not in a lip pucker $(p=0.259, r=-0.156)$. However, the only individual with impaired lip pucker according to their Sunnybrook Facial Grading System score had very weak lips (case 11).

\section{Discussion}

Congenital facial nerve palsy is one of the anomalies that can be associated with thalidomide embryopathy, and it is often combined with ocular motility defects caused by abducens nerve palsy. ${ }^{2,10}$ This combination of symptoms is also known as Möbius sequence and is recognised as a possible sign of an early embryonic insult. ${ }^{11}$ The facial palsy seen in Möbius sequence is often bilateral; in contrast, the congenital palsy seen in the present study was unilateral. ${ }^{12}$ Congenital facial palsy is also a frequent finding in other conditions involving malformations caused by early pregnancy incidents, such as Goldenhar syndrome and 'CHARGE' syndrome (the latter comprising coloboma, heart abnormalities, retardation of growth and/ or development, and genital and ear anomalies). ${ }^{13-17}$

Five individuals (16 per cent) in the present study had a previous diagnosis of facial palsy, and one had bilaterally incomplete facial movements because of Parkinson's disease. Three individuals (10 per cent) had an acquired facial palsy, of whom two already had congenital nerve palsy on the opposite side. This is more than can be expected by chance, and may indicate that the facial nerve is more vulnerable in this population. ${ }^{18}$ There was no characteristic feature of impaired facial expression in the group. Sometimes, only one single branch of the facial nerve seemed to be affected. The facial palsy interfered with facial expression and facial appearance, but speech was affected (i.e. dysarthria was present) only when there was bilateral impairment.

Lip force and the mean value for mouth width change in an open mouthed smile were reduced for 
TABLE III

LIP MOBILITY RESULTS*: TE CASES WITH NO KNOWN FACIAL PALSY AND CONTROLS

\begin{tabular}{|c|c|c|c|c|c|c|}
\hline \multirow[t]{2}{*}{ Facial expression } & \multicolumn{3}{|c|}{$\mathrm{TE}^{\dagger}$} & \multicolumn{3}{|c|}{ Controls $^{\dagger}$} \\
\hline & MW (mm) & MWC (mm) & MWA (\%) & MW (mm) & MWC (mm) & MWA (\%) \\
\hline Mouth at rest & $49.6 \pm 3.9$ & - & $4.5 \pm 5.2$ & $49.2 \pm 4.5$ & - & $5.0 \pm 3.1$ \\
\hline Open mouthed smile & $61.4 \pm 4.4$ & $11.8 \pm 3.7$ & $3.8 \pm 4.7$ & $65.8 \pm 4.3$ & $16.6 \pm 3.1$ & $3.4 \pm 2.2$ \\
\hline Lip pucker & $30.8 \pm 4.0$ & $-18.8 \pm 5.2$ & $9.4 \pm 7.9$ & $29.0 \pm 4.8$ & $-20.2 \pm 4.9$ & $10.5 \pm 8.9$ \\
\hline
\end{tabular}

Data represent means \pm standard deviations. ${ }^{*}$ Mouth width $(\mathrm{MW})$, mouth width change from rest to maximal expression (MWC) and relative mouth width asymmetry (MWA), from three-dimensional motion analysis of lip mobility. ${ }^{\dagger} N=25$. TE $=$ thalidomide embryopathy cases with no known facial palsy

thalidomide embryopathy individuals without facial impairment, compared with healthy individuals. This could imply that some individuals with thalidomide embryopathy had a mild facial weakness that had not been clinically identified.

Following subjective evaluation of the facial muscles, assessment was completed by taking objective measurements of lip mobility and lip force, via computerised video analysis and a lip force measuring device. Results from the measuring devices confirmed most of the subjective evaluations; however, there was a risk that all results may have been affected by the fact that the examiners were not blinded to the participants' thalidomide diagnosis. In two cases, there was a discrepancy between the results of objective and subjective evaluation of facial asymmetry at rest. This discrepancy could be due to the fact that subjective evaluation involved the whole face, whereas objective measurements were calculated only from the three-dimensional position of the oral commissures.

In their 2010 methodological study, Sjögreen et al. explored the same quantitative methods for evaluation of lip mobility and lip force which were used in the present study. ${ }^{8}$ This study suggested threshold values for lip force (12 Newton) and mouth width change in

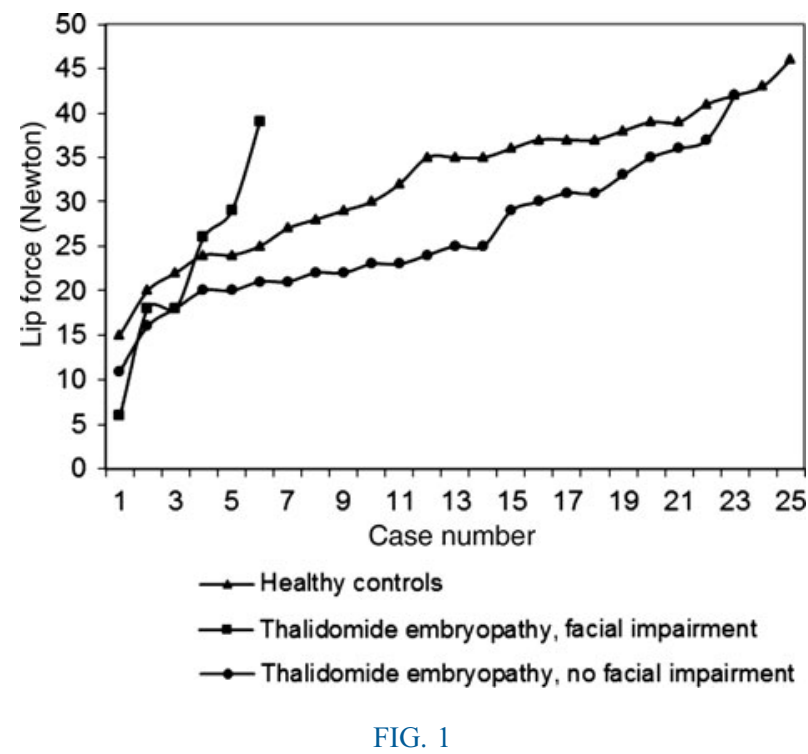

Maximal lip force measured in 29 thalidomide embryopathy individuals and 25 healthy controls, using the LF100 instrument. open mouthed smile $(9 \mathrm{~mm})$ and in a lip pucker $(11 \mathrm{~mm})$ which could identify adults with impaired lip function. The suggested thresholds for lip force and for mouth width change in a lip pucker were observed to be adequate for predictive purposes in the present study. However, the suggested threshold for mouth width change in an open mouthed smile seemed to be less able to predict impaired lip function.

- Thalidomide embryopathy can cause skeletal, ear and eye abnormalities and facial palsy

- This study assessed facial expression in thalidomide embryopathy patients

- There was no typical pattern of facial palsy severity or distribution

- All patients with facial palsy also had impaired eye motility

- Patients without substantial facial impairment had poorer lip force and mobility

The present study contributes to the overall picture of thalidomide embryopathy by adding a description of how facial expression can be affected in this condition. There seems to be no typical expression of facial palsy in thalidomide embryopathy, regarding severity and distribution.

\section{Conclusion}

Individuals with thalidomide embryopathy can have skeletal deformities, ear and eye aberrations, and facial palsy. This study gives a more detailed description of how individuals' facial expression can be affected by this condition.

We found that there was no typical expression of facial palsy in thalidomide embryopathy, regarding severity and distribution. All individuals with thalidomide embryopathy and facial palsy also had impaired eye motility. Individuals with thalidomide embryopathy who did not have clinically diagnosed facial impairment were observed to have significantly weaker lips and more restricted lip mobility, compared with healthy controls. 


\section{Acknowledgements}

We thank dental nurse Linda Tjärnström Gustafsson for invaluable assistance with practical procedures, and speech-language pathologist Åsa Mogren for help with the assessments. Special thanks also go to Professor Anette Lohmander and Professor Kerstin Strömland for contributing their knowledge and expertise. We are also grateful to the other members of the multidisciplinary team involved in the project for their fruitful cooperation, and to all the individuals who participated in the study.

\section{References}

1 Lenz W. A short history of thalidomide embryopathy. Teratology 1988;38:203-15

2 Strömland K, Miller MT. Thalidomide embryopathy: revisited 27 years later. Acta Ophthalmol (Copenh) 1993;71:238-45

3 Ekfeldt A, Carlsson GE. Dental status and oral function in an adult group of subjects with thalidomide embryopathy - a clinical and questionnaire study. Acta Odontol Scand 2008;66: 300-6

4 Miller MT, Strömland K, Ventura L. Congenital aberrant tearing: a re-look. Trans Am Ophthalmol Soc 2008;106:100-16

5 Ross BG, Fradet G, Nedzelski JM. Development of a sensitive clinical facial grading system. Otolaryngol Head Neck Surg 1996;114:380-6

6 Neely JG, Cherian NG, Dickerson CB, Nedzelski JM. Sunnybrook facial grading system: reliability and criteria for grading. Laryngoscope 2010;120:1038-45

7 Schimmel M, Christou P, Houstis O, Herrmann FR, Kiliaridis S, Muller F. Distances between facial landmarks can be measured accurately with a new digital 3-dimensional video system. Am J Orthod Dentofacial Orthop 2010;137:580.e1-10

8 Sjögreen L, Lohmander A, Kiliaridis S. Exploring quantitative methods for evaluation of lip function. J Oral Rehabil 2011; 38:410-22

9 Hägg M, Olgarsson M, Anniko M. Reliable lip force measurement in healthy controls and in patients with stroke: a methodologic study. Dysphagia 2008;23:291-6

10 Miller MT, Strömland K. Ocular motility in thalidomide embryopathy. J Pediatr Ophthalmol Strabismus 1991;28:47-54
11 Marques-Dias MJ, Gonzalez CH, Rosemberg S. Möbius sequence in children exposed in utero to misoprostol: neuropathological study of three cases. Birth Defects Res A Clin Mol Teratol 2003;67:1002-7

12 Sjögreen L, Andersson-Norinder J, Jacobsson C. Development of speech, feeding, eating, and facial expression in Möbius sequence. Int J Pediatr Otorhinolaryngol 2001;60:197-204

13 Strömland K, Miller M, Sjögreen L, Johansson M, Joelsson BM, Billstedt E et al. Oculo-auriculo-vertebral spectrum: associated anomalies, functional deficits and possible developmental risk factors. Am J Med Genet A 2007;143A:1317-25

14 Touliatou V, Fryssira H, Mavrou A, Kanavakis E, Kitsiou-Tzeli S. Clinical manifestations in 17 Greek patients with Goldenhar syndrome. Genet Couns 2006;17:359-70

15 Carvalho GJ, Song CS, Vargervik K, Lalwani AK. Auditory and facial nerve dysfunction in patients with hemifacial microsomia. Arch Otolaryngol Head Neck Surg 1999;125:209-12

16 Blake KD, Hartshorne TS, Lawand C, Dailor AN, Thelin JW. Cranial nerve manifestations in CHARGE syndrome. $\mathrm{Am} J$ Med Genet A 2008;146A:585-92

17 Strömland K, Sjögreen L, Johansson M, Ekman Joelsson B-M, Miller M, Danielsson S et al. CHARGE association in Sweden: malformations and functional deficits. Am J Med Genet A 2005; 133A:331-9

18 Katusic SK, Beard CM, Wiederholt WC, Bergstralh EJ, Kurland LT. Incidence, clinical features, and prognosis in Bell's palsy, Rochester, Minnesota, 1968-1982. Ann Neurol 1986;20:622-7

Address for correspondence:

Dr Lotta Sjögreen,

Mun-H-Center, Odontologen,

Medicinaregatan $12 \mathrm{~A}$,

SE-413 90 Göteborg, Sweden

Fax: + 46317509201

E-mail: lotta.sjogreen@vgregion.se

Dr L Sjögreen takes responsibility for the integrity of the content of the paper

Competing interests: None declared 